\title{
A Relevância da Ração Animal para o Preço da Carne de Frango
}

\author{
The Relevance of Animal Feed for the Price of Chicken Meat
}

\author{
Sarita Mercedes Fernandez ${ }^{1}$ \\ Daniela Garcez Wives ${ }^{2}$ \\ Marlise Amália Reinehr Dal Forno ${ }^{3}$ \\ Marcia dos Santos Ramos ${ }^{4}$
}

\begin{abstract}
RESUMO: O artigo tem o objetivo geral de apresentar o panorama estatístico dos fatores que contribuem na formação global dos preços, além do contexto mundial da produção, consumo, exportação e importação da carne de frango. O objetivo específico é identificar as variáveis que influenciam o preço global da carne de frango. A pesquisa é subdividida em análise descritiva, inferencial (Testes Paramétricos) e análise multivariada (Regressão Linear Simples e Múltipla). Os principais resultados da pesquisa indicaram que os preços do milho e da soja influenciam o preço final da carne de frango do Brasil, China e Rússia. Os testes paramétricos constataram que o preço da carne de frango no Brasil e EUA diferiram do preço na Rússia e China. Considerase, finalmente, que o incremento mundial do preço da carne de frango pode ser afetado pelo preço do milho e da soja, grãos constituintes das rações para alimentação animal.

Palavras-chave: preços, agroalimentar, incerteza
\end{abstract}

ABSTRACT: The paper has the general aim of presenting the statistical picture of the factors that contribute to the overall price formation, beyond the context of global production, consumption, export and import of chicken meat. The research is divided into descriptive, inferential analysis (parametric tests) and multivariate analysis (Simple and Multiple Linear Regression). The main results of the research indicated that the prices of maise and soybeans influence the final price of chicken meat from Brazil, China and Russia. Parametric tests found that the price of chicken meat in Brazil and the USA differ in price in Russia and China. Finally, it is considered that the global rise in the price of chicken meat can be affected by the price of maise and soybean constituents of feed grains for animal feed.

Keywords: prices, agrifood, uncertainty

Código JEL: D24

\section{INTRODUÇÃO}

Os preços mundiais dos alimentos vêm apresentando uma tendência de elevação, destacando-se o preço da carne de frango e dos grãos, milho e soja. Paralelamente, os países considerados emergentes, com o incremento do poder aquisitivo de seus habitantes, como o Brasil, Rússia, Índia e China, estão incluindo em suas dietas alimentares uma maior quantidade de proteínas. Essa mudança no padrão de consumo vem afetando a economia global e a carne de frango tem sido considerada uma das principais fontes de proteína utilizada para

\footnotetext{
${ }^{1}$ Mestre em Fitotecnia e em Desenvolvimento Rural pela Universidade Federal do Rio Grande do Sul (UFRGS)

${ }^{2}$ Pós-doutoranda em Desenvolvimento Rural pela Universidade Federal do Rio Grande do Sul (UFRGS)

${ }^{3}$ Doutora em Geografia pela Universidade Federal do Rio Grande do Sul (UFRGS)

${ }^{4}$ Pós-doutoranda em Desenvolvimento Rural pela Universidade Federal do Rio Grande do Sul (UFRGS)
} 
alimentação, em países de economias avançadas ou, em desenvolvimento (FAO, 2011).

Tendo em vista a importância da carne de frango para a economia brasileira, o artigo tem o objetivo geral de apresentar o panorama estatístico dos fatores que contribuem na formação global dos preços, desta commodity. A questão central do trabalho concentra-se em identificar as variáveis que influenciam o preço global da carne de frango, dada a problemática da maior demanda mundial e a menor oferta causada por fatores, que decorrem principalmente dos altos custos dos insumos, em especial, das rações à base de grãos para alimentação dos animais. Porém, ressalta-se que não será realizada uma análise econométrica, procurando-se evidenciar tendências estatísticas e a sua condição preditiva.

\section{CONTEXTO MUNDIAL DA PRODUÇÃO, CONSUMO, EXPORTAÇÃO E IMPORTAÇÃO DA CARNE DE FRANGO}

O ranking de produção no mercado global de carne de frango é liderado pelos Estados Unidos, seguido pela China, Brasil e União Europeia; a Índia e a Rússia apresentam um menor desempenho (USDA, EMPRAPA/CIAS, 2012). Os países em destaque no comércio mundial da carne de frango vêm sobressaindose devido a excelência no manejo do efetivo, melhoramento genético do plantel, ou seja, a eficiência tecnológica tem sido responsável, em grande parte, pelos bons resultados obtidos. Embora o Brasil ocupe, atualmente, a terceira colocação quanto à produção mundial, vem destacando-se como um dos principais países emergentes na avicultura de corte. Os países considerados emergentes pertencem ao BRIC (Brasil, Rússia, Índia e China) grupo idealizado pelo Goldman Sachs Research Economic Group (O'NEILL, 2001).

O número de aves por plantel aumentou na razão de $400 \%$, assim como a produtividade da massa corporal, por animal. A razão da quantidade de carne produzida por animal em estoque, ou razão "off-take", calculada em função da produção bruta local, dividida pelo número total de animais do plantel foi incrementada significativamente ao longo do período de 2005 a 2012, com previsão de seguir essa tendência até 2021, segundo a Organisation for Economic Co-Operation and Development (OECD) /Food and Agriculture Organization Of the United Nations (FAO) (OECD/FAO, 2012). Destaca-se o Brasil, quanto ao índice de produtividade da carne de frango. 
Figura 01: Mapa da distribuição do rebanho de frangos (em cabeças) no ano de 2010, no mercado global.

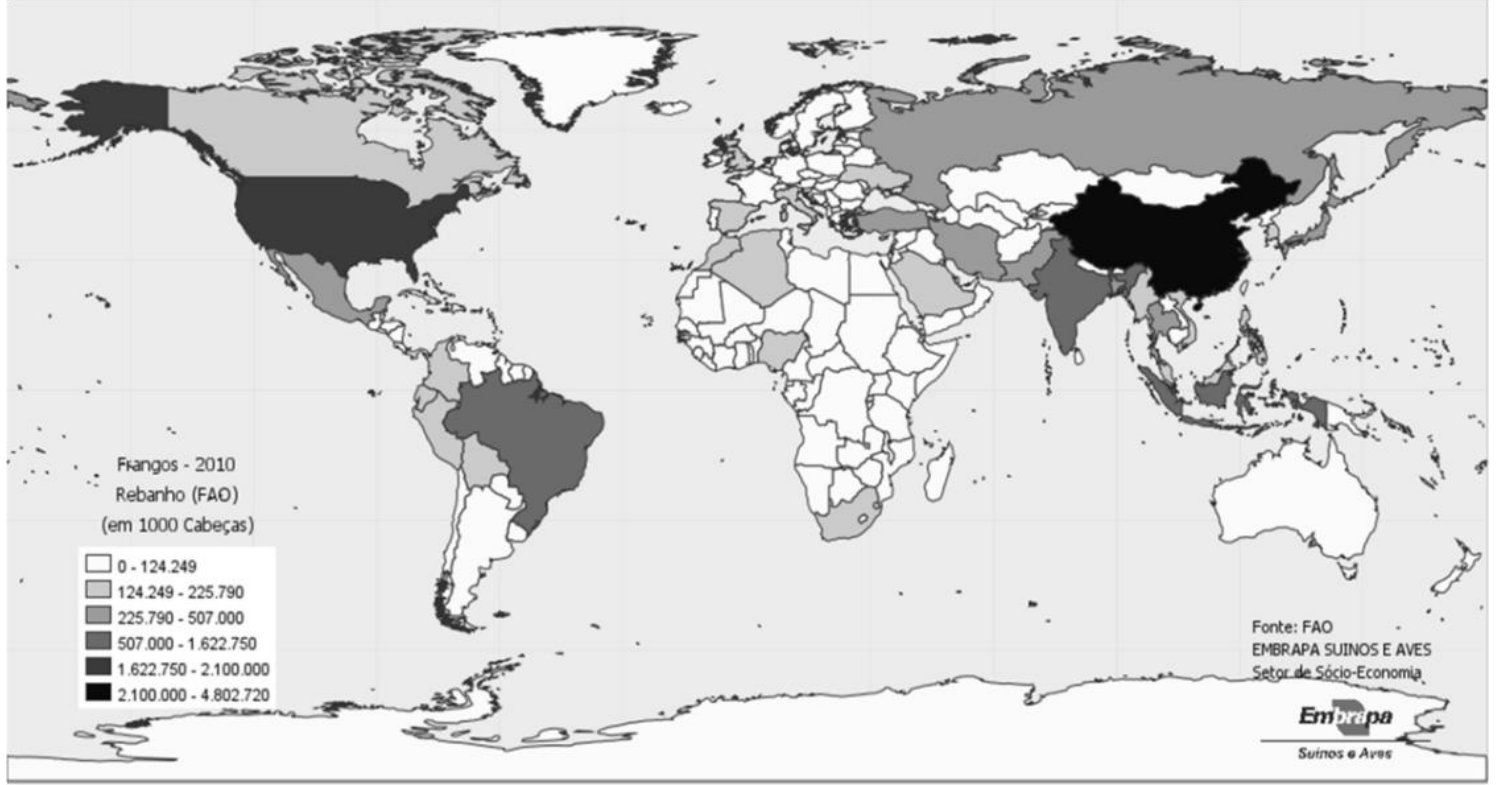

Fonte: FAO, EMBRAPA/CIAS (2010).

Nunes (2012), especialista brasileiro do setor avícola, prevê que até 2030 a produção de frango deve crescer em torno de $80 \%$ no mercado global, chegando até $240 \%$, em 2050 . A situação mundial do efetivo é liderada por cinco países, são eles: a China, Estados Unidos, Indonésia, Brasil e Índia, como se observa na Figura 1. No Brasil, o efetivo é mais concentrado nos Estados do Paraná, São Paulo, Santa Catarina, Rio Grande do Sul e Minas Gerais, segundo - United States Department of Agriculture (USDA), e Empresa Brasileira de Pesquisa Agropecuária (EMBRAPA) / Centro de Informações em Aves e Suínos (CIAS).

Embora a crise europeia tenha gerado algumas dúvidas para o cenário econômico, reduzindo o consumo de carnes em geral e incrementando o consumo de grãos para alimentação humana, a tendência do setor avícola é de crescimento, devido ao aumento gradual do consumo de proteínas na dieta alimentar mundial. Uma das medidas adotadas pelo setor, no Brasil, para colocação do produto no mercado internacional foi o corte da produção em 10\%, evitando a super oferta da carne devido à redução do poder de compra do mercado europeu. Já que o frango possui proteínas de qualidade e o preço da carne é acessível em relação a outros tipos encontrados no mercado, apresentando versatilidade quanto ao preparo para alimentação (NUNES, 2012).

Nas exportações da commodity em 2012, nota-se um destaque brasileiro, com cerca de 3.500 .000 toneladas, em relação aos Estados Unidos e União Européia, com cerca de 3.000.000 toneladas exportadas, a China, Rússia e Índia apresentaram resultados inferiores, com 445.000, 50.000 e 10.000 toneladas, respectivamente (USDA, EMPRAPA/CIAS, 2012). As importações de carne de frango são lideradas por cinco países; Japão, Arábia Saudita, União Européia, México e Rússia, figura seis. Observa-se que a China, Estados Unidos e Brasil não têm importações expressivas, no ano de 2012 (USDA, EMPRAPA/CIAS, 2012). 
Os dados apresentados na explanação anterior foram originados nas bases USDA e EMBRAPA, são corroborados no último relatório da OECD/FAO que afirma o crescimento da demanda de carne de frango pelas grandes economias da Ásia e de países exportadores de petróleo, sendo essa tendência também acompanhada pelos países emergentes. (OECD; FAO, 2012).

\section{O PREÇO DA CARNE DE FRANGO NO MERCADO GLOBAL}

Como mencionado anteriormente, a produção mundial de frango vem crescendo nos últimos anos, assim como o preço do produto praticado no mercado global. Existe um incremento dos preços nominais, ou seja, sem o reajuste da inflação, ao longo das últimas décadas como podemos observar nos dados apresentados na Figura 2. A qual demonstra a tendência da razão off-take do Brasil, Rússia, Índia, China e Estados Unidos (2005-09), neste critério há um destaque importante do Brasil. Já em relação ao crescimento percentual da razão de 1985-2011 destaca-se a Rússia e a India. Porem o maior destaque para os anos de 2012-21, em relação a previsão percentual (off-take) é dos Estados Unidos.

Figura 02: Tendência da razão off-take* do Brasil, Rússia, Índia, China e Estados Unidos (2005-09), crescimento percentual da razão de 1985-2011 e previsão percentual anual de 2012-21.

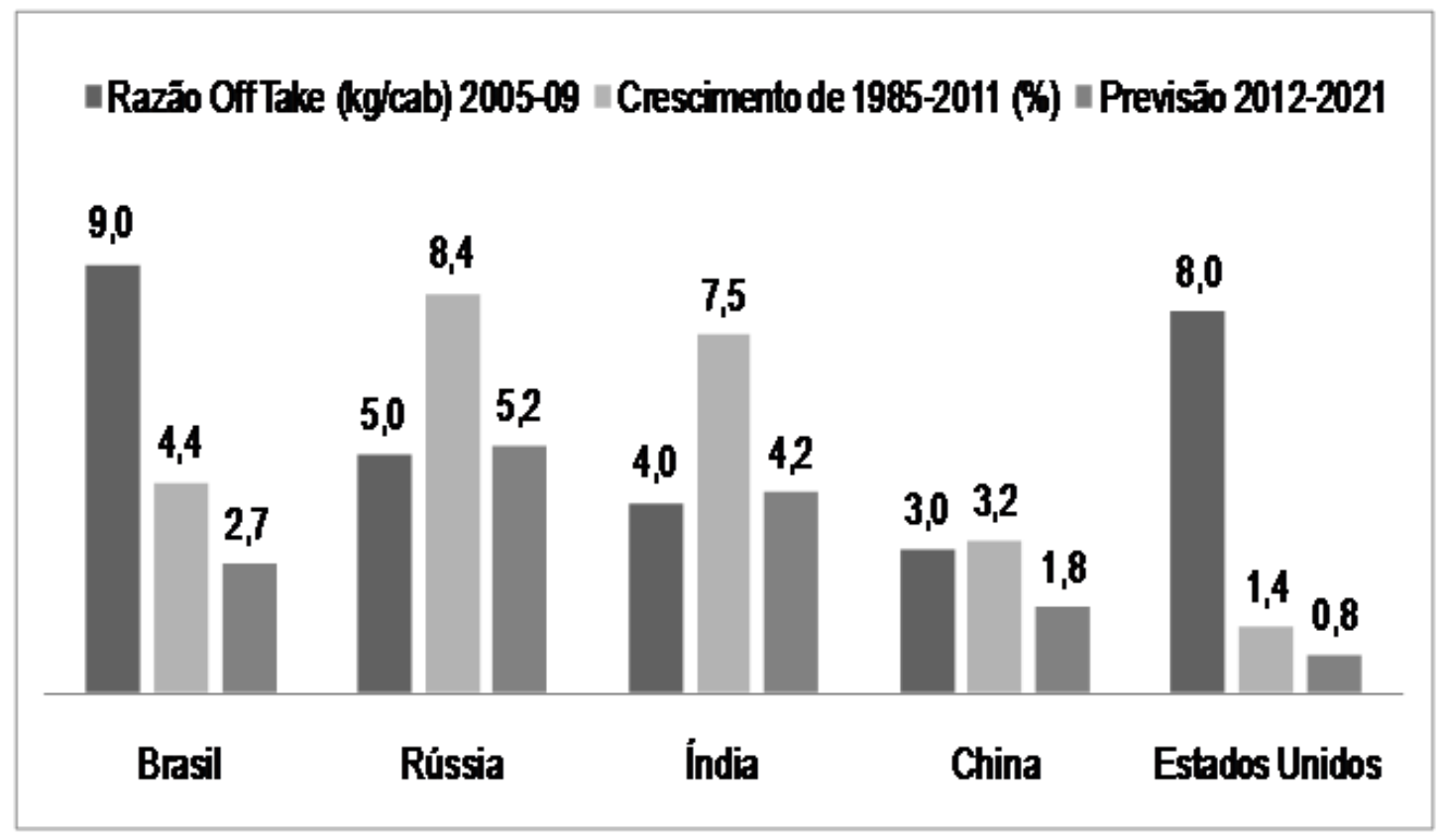

Fonte: OECD/ FAO (2012).

Ao analisar uma trajetória histórica dos preços do frango no caso Brasileiro conforme Miele e Girotto (2005) observa-se que os preços recebidos pela carne de frango brasileira nos últimos 20 anos oscilaram entre US $\$ 0,673 \mathrm{e}$ US $\$ 1,250$. Os autores apontam que a média do período, apresentaria uma oscilação de aproximadamente $30 \%$ para mais e para menos, o que aponta para uma certa volatilidade nos preços praticados internacionalmente. entretanto 
como pode-se observar nos dados da figura 3 no período que vai de 2019 à 2012 a uma crescente na nos preços praticados mundialmente.

Figura 03: Índice de preço do mercado global de carne de ave, de 2009 ao segundo trimestre de 2012, segundo dados do FMI (dólares por tonelada).

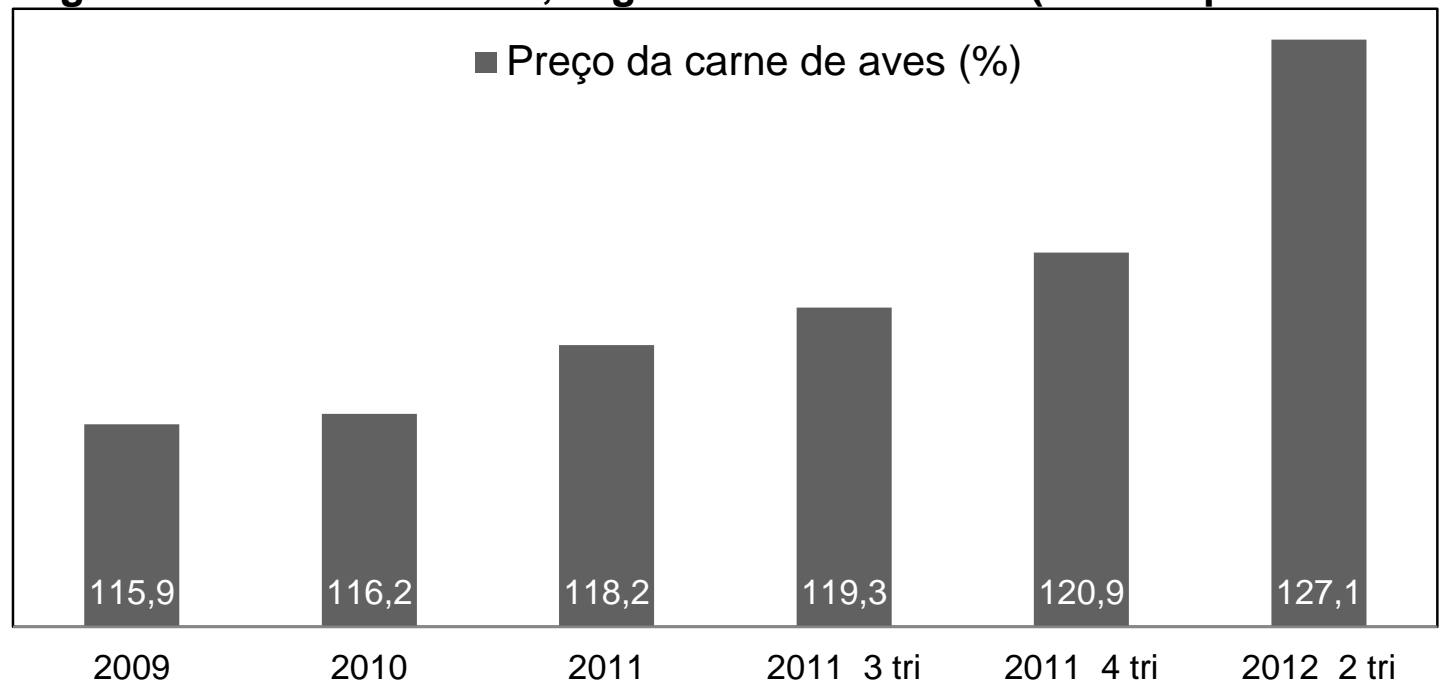

Fonte: FMI (2012).

Alguns fatores colaboram para a elevação dos preços da carne de frango e segundo a OECD/FAO (2012), destaca-se o forte aumento dos preços dos grãos utilizados na composição das rações, usadas para a alimentação dos animais.

Os custos da cadeia agroindustrial, segundo a OECD e FAO, também estão sendo afetados pelo preço dos insumos, principalmente das rações a base de grãos, além dos custos com energia, transporte, garantia da segurança alimentar dos consumidores, questões ambientais e novas normas de regulamentação de bem estar animal. Além desses fatores a competição por terra e água deverá exercer influência sobre a produção e, consequentemente, sobre a oferta dos produtos à base de carne de frango. Porém, as projeções da FAO para 2021 são positivas para o mercado avícola, indicando que haverá, em média, o crescimento de 2,2\%, ao ano (OECD; FAO, 2012).

As previsões da OECD/FAO estão sujeitas a alterações, em decorrência de possíveis mudanças do cenário macroeconômico, além de medidas antidumping, que podem ser impostas pelos países importadores a fim de proteger o funcionamento do mercado interno e a garantia de abastecimento local.

Esses fatores que podem provocar a elevação dos preços podem ser analisados sob o enfoque teórico do conceito de incerteza. Duncan (1972) aplica o conceito de incerteza para ambientes onde existe a impossibilidade da previsão confiável devida a ação de vários fatores interdependentes, onde a geopolítica pode afetar o resultado final das possíveis previsões de um cenário econômico, ou de um ambiente de comércio global, como as previsões da OECD/FAO, abordadas no trabalho. 
Quadro 1: evolução do conceito de incerteza

\begin{tabular}{|c|c|c|}
\hline Autor & Evolução do conceito INCERTEZA & Referências \\
\hline $\begin{array}{l}\text { Knight } \\
(1921)\end{array}$ & $\begin{array}{l}\text { A incerteza é uma probabilidade } \\
\text { imensurável, quando mensurável } \\
\text { transforma-se em risco. }\end{array}$ & $\begin{array}{l}\text { KNIGHT, F. Risk, urcertainty and profit. } \\
\text { London: Houghton Mifflin, } 1921 .\end{array}$ \\
\hline $\begin{array}{l}\text { Coase } \\
(1937)\end{array}$ & $\begin{array}{l}\text { Os custos e as falhas de mercado } \\
\text { decorrem de um ambiente incerto }\end{array}$ & $\begin{array}{l}\text { COASE, R. The nature of the firm. Economica } \\
\text { New Series, Ano } 1937 \text {, nro. } 16 \text {, v. } 4 \text {, p. } 386-405 \text {. }\end{array}$ \\
\hline $\begin{array}{l}\text { Koopmans } \\
\text { (1957) }\end{array}$ & $\begin{array}{l}\text { O conceito de incerteza é primário, } \\
\text { marcado pela falta de conhecimento } \\
\text { sobre mudanças climáticas, também } \\
\text { por alterações nas preferências de } \\
\text { consumo da população; e } \\
\text { secundariamente, pelas falhas no } \\
\text { processo de decisão, e ainda pelas } \\
\text { mudanças de estratégia das firmas } \\
\text { concorrentes, }\end{array}$ & $\begin{array}{l}\text { KOOPMANS, T. Three essays on the state of } \\
\text { economic science. New York: McGraw-Hill, } \\
1957 .\end{array}$ \\
\hline $\begin{array}{c}\text { Duncan } \\
(1972)\end{array}$ & $\begin{array}{l}\text { O conceito de incerteza aplica-se para } \\
\text { ambientes onde existe a } \\
\text { impossibilidade da previsão confiável } \\
\text { devida a ação de vários fatores } \\
\text { interdependentes, onde a geopolítica } \\
\text { pode afetar o resultado final das } \\
\text { possíveis previsões de um cenário } \\
\text { econômico, ou de um ambiente de } \\
\text { comércio global }\end{array}$ & $\begin{array}{l}\text { DUNCAN, R. G. Characteristics of } \\
\text { organizational environment and perceived } \\
\text { environmental uncertainty. Administrative } \\
\text { Science Quarterly, Ano 1972. nro. 2, v. 17, p. } \\
\text { 313-327. }\end{array}$ \\
\hline $\begin{array}{l}\text { Arrow } \\
(1974)\end{array}$ & $\begin{array}{l}\text { A incerteza é um estado em que não se } \\
\text { conhece totalmente o mundo, não se } \\
\text { conhecendo seu estado verdadeiro. }\end{array}$ & $\begin{array}{l}\text { ARROW, K. The limits of organization. New } \\
\text { York: Norton, } 1974 .\end{array}$ \\
\hline $\begin{array}{l}\text { Willianson } \\
\text { (1975) }\end{array}$ & $\begin{array}{l}\text { Os eventos são dotados de uma } \\
\text { complexidade permeada pela } \\
\text { racionalidade limitada dos gestores. }\end{array}$ & $\begin{array}{l}\text { WILLIAMSON, O. E. Markets and hierarchies: } \\
\text { analysis and antitrust implications. New York: } \\
\text { Free Press, } 1975 .\end{array}$ \\
\hline $\begin{array}{l}\text { Willianson } \\
\quad(1985)\end{array}$ & $\begin{array}{l}\text { Existem } 3 \text { tipos de incerteza: a primária } \\
\text { permeada por contingências } \\
\text { ambientais e alterações da preferência } \\
\text { dos consumidores; a segunda, } \\
\text { ausência de informações para a } \\
\text { tomada de decisão frente às mudanças } \\
\text { de mercado e concorrência; e a } \\
\text { terceira que refere-se à estratégia e } \\
\text { comportamento dos concorrentes } \\
\text { (oportunismo). }\end{array}$ & $\begin{array}{l}\text { WILLIAMSON, O. E. The economic institutions } \\
\text { of capitalism. New York: Free Press, } 1985 .\end{array}$ \\
\hline $\begin{array}{l}\text { Milliken } \\
(1987)\end{array}$ & $\begin{array}{l}\text { A fonte da incerteza é o ambiente } \\
\text { externo das organizações }\end{array}$ & $\begin{array}{l}\text { MILLIKEN, F. J. Three types of Perceived } \\
\text { Uncertainty about the Environment: State, } \\
\text { Effect, and Response Uncertainty. Academy of } \\
\text { Management Review, Ano } 1987 \text { Nro. 1, Vol. 12, } \\
\text { p.133-143. }\end{array}$ \\
\hline $\begin{array}{l}\text { Jusoh } \\
(2010)\end{array}$ & $\begin{array}{l}\text { A incerteza ambiental é percebida } \\
\text { como um proxy para as variáveis } \\
\text { externas à organização e serve para } \\
\text { explicar variações na escolha de } \\
\text { medidas de desempenho_das firmas. }\end{array}$ & $\begin{array}{l}\text { JUSOH, R. (2010). The influence of perceived } \\
\text { environmental uncertainty, firm size, and } \\
\text { strategy on multiple performance measures } \\
\text { usage. African Journal of Business } \\
\text { Management, Ano 2010, Nro.10, Vol. 4, p. 1972- } \\
\text { 1984. } \\
\text { em://www.academicjournals.org/ajbm. Disponível }\end{array}$ \\
\hline
\end{tabular}

Fonte: Elaborado pelos autores a partir das obras de ARROW (1974), COASE (1937), DUNCAN (1972), JUSOH (2010), KNIGHT (1921), KOOPMANS (1957) e WILLIANSON (1975 e 1985).

O trecho do documento do FMI (2012) transcrito a seguir, sobre perspectivas da economia mundial, também pode reforçar o conceito de incerteza de Duncan (1972) evidenciando a influência do déficit de produção de produtos alimentícios sobre o preço dos grãos e das rações para alimentação animal: 


\begin{abstract}
"Ante a falta de reservas alimentícias adequadas, a ameaça de um déficit de produção provocou uma resposta imediata dos preços dos grãos, que repercute significativamente em outras matérias primas alimentares. Os crescentes preços do milho em particular têm importante efeito nos mercados da carne e do etanol em 2012. Este ano se prevê que a totalidade do crescimento do consumo de milho nos Estados Unidos obedecerá ao seu emprego para alimentação animal" (FMI, 2012, p. 42-43).
\end{abstract}

Percebe-se, no texto do FMI (2012) que existe a incerteza sobre a produção para atender a demanda devida a falta de reservas alimentícias, provocando a alta dos preços dos grãos. O trabalho de Rodriguéz (2010) analisa a incerteza de Duncan (1972) utilizando o conceito de turbulência.

\begin{abstract}
"A turbulência significa sempre um aumento do risco e da incerteza, é uma medida de aleatoriedade do estado do entorno. Ainda que não se possa prever com certeza o estado futuro do meio externo, apresentando-se alternativas, de estados futuros, cada um dos quais tem uma probabilidade de ocorrência" (RODRIGUÉZ, 2010, p. 22).
\end{abstract}

Outros autores também trabalharam o conceito de incerteza levando em consideração vários aspectos que podem ser visualizados no quadro 1.

No presente artigo trabalhou-se sob a luz da incerteza global para a tomada de decisão. O sistema global de preço dos alimentos, por si só, já compreende ambientes de decisão sob a incerteza, seja do melhor preço, da disponibilidade do produto, das condições climáticas que interferem nos preços, no momento das negociações, ou mesmo as situações de oportunismo dos agentes econômicos.

Os mercados agrícolas dependem diretamente dos insumos, da energia, do transporte, do clima e de outros fatores que irão determinar o preço dos alimentos no sistema global. A crise europeia e a seca nos Estados Unidos podem ter tido um efeito direto sobre a oferta, assim como na demanda dos grãos e, consequentemente, sobre a alimentação a base de ração para a produção de carne, provocando a alta dos preços dos produtos no período entre 2009 e 2012, evidenciando a incerteza desses mercados.

\title{
4. METODOLOGIA
}

Após verificar-se que existia uma tendência de elevação dos preços da carne de frango a nível mundial, com destaque para os países emergentes, além do preço da ração e dos seus principais componentes, o milho e a soja, foram realizadas análises de correlação de Pearson. Mais tarde, procederam-se as análises de regressão para a confirmação da influência do preço dos principais grãos, constituintes da ração avícola, sobre o preço da carne de frango. 
Para a realização do tratamento dos dados, do teste de médias às análises de regressão, foi utilizado o software $R$. Foi então empregada uma série temporal da FAO, disponível na Internet através do banco de dados FAOSTAT.

Segundo Morettin (2006, p.1), "uma série temporal é qualquer conjunto de observações ordenadas no tempo". A série utilizada na pesquisa compreendeu dez anos, de 2000 a 2010. Porém, pela ausência de alguns meses do ano de 2010, optou-se pela realização da análise no período de 2000 a 2009.

Então, foram computados os dados diários mensais dos preços da carne de frango, do milho em grão e da soja em grão e depois realizada a média mensal que compôs a amostra. Num total de quatro países analisados, num período de 12 meses por ano, durante nove anos.

No mercado global, foram eleitos os países que integram o BRIC; Brasil, Rússia e China, além dos Estados Unidos. A Índia não foi analisada por insuficiência de dados sobre o preço da carne de frango. Os Estados Unidos foram escolhidos em função da sua representatividade para o mercado mundial no setor avícola.

Foram utilizados os países do BRIC devido à tendência verificada pelas leituras e pela observação de que há um incremento do poder aquisitivo de países emergentes, o que vem proporcionado um maior consumo de proteínas de origem animal, principalmente de frango.

Procedeu-se realizando análise de variância, a qual é um teste de médias, onde a estatística utilizada é a F. O teste é realizado sob a hipótese nula de não haver diferença entre as médias dos tratamentos; em que nesse caso, os tratamentos foram considerados os países.

Verificou-se que o teste foi altamente significativo, ou seja, há evidências para dizer que existe diferença significativa entre as médias dos preços de frango dos países; Brasil, China, Rússia e EUA. As condições de normalidade dos resíduos e independência dos erros foram satisfeitas.

A análise multivariada utilizada consiste num método estatístico capaz de realizar múltiplas medidas do objeto de pesquisa sob investigação (Hair, Jr. et al., 2005). A análise de regressão múltipla escolhida para a pesquisa é "uma técnica estatística que pode ser usada para analisar a relação entre uma única variável dependente (critério) e várias variáveis independentes (preditoras)" (Hair, Jr. et al., 2005). Em séries temporais o "único propósito da previsão e interpretação dos resultados é útil somente para aumentar a precisão preditiva" (Hair, Jr. et al., 2005).

O modelo de regressão múltipla, segundo Johnson \& Wichern (2002), pode ser representado por:

$$
\hat{Y}_{i}=\hat{\beta}_{0}+\hat{\beta}_{1} X_{1 i}+\hat{\beta}_{2} X_{2 i}+\cdots+\hat{\beta}_{p} X_{p i}, i=1,2, \cdots, n .
$$

Onde o erro de previsão do modelo é representado por:

Para o trabalho:

$$
\varepsilon=Y-X \beta
$$

$\wedge$

$\beta_{0}=$ preço da carne de frango independentemente do preço do milho e da soja $\wedge$

$\beta_{1}=$ variação do preço da carne de frango em relação à unidade de variação do preço do milho 
$\wedge$

$B_{2}=$ variação do preço da carne de frango em relação à unidade de variação do preço da soja

$\mathrm{X}_{1}=$ preço do milho

$\mathrm{X}_{2}=$ preço da soja

\section{RESULTADOS E DISCUSSÃO}

O mercado global depende de fatores complexos que determinam as estratégias dos países. O ambiente das negociações são, muitas vezes dependentes de fatores imprevisíveis e dinâmicos, a exemplo da seca nos Estados Unidos. Embora existam métodos e equipamentos que podem minimizar as consequências negativas em rodadas de decisão sobre a mitigação dos efeitos climáticos, para a agricultura e a pecuária, muitas vezes os critérios de sustentabilidade não são respeitados. De outra forma, também podem ser criados modelos para a compreensão dos fenômenos envolvidos nas negociações globais dos preços dos alimentos.

Milliken (2001) aponta que o rótulo ambiental atrelado ao termo incerteza sugere que a fonte da incerteza é o ambiente externo das organizações. $E$, Jusoh (2010) acrescenta que ".a importância da incerteza ambiental percebida como um proxy para as variáveis externas à organização serve para explicar variações na escolha de medidas de desempenho como relatado em estudos anteriores." (Milliken, p.136; Jusoh, p.1.981).

Então foi estabelecido um modelo para evidenciar os fatores internos envolvidos no ambiente da produção de carne de frango, no mercado externo, dos países do BRIC para tentar relacionar a influência dos preços do milho e da soja sobre o preço da carne de frango.

A análise realizada na pesquisa compara os preços da carne de frango com o preço do milho e da soja em grão. Além disso, é realizado um comparativo entre os países para verificar se existem preços da carne, praticados no mercado global, semelhantes.

Convém esclarecer-se que segundo Knight (1921) a probabilidade estatística é uma generalização empírica, ou "uma avaliação empírica da frequência de associação entre predicados" (KNIGHT, 1921, p.225). Aqui não nos deteremos em avaliação econométrica das variáveis, mas será testada a associação entre as variáveis que influenciam o preço da carne de frango.

Para serem conhecidas as médias que diferiram foi realizado o teste de comparação múltipla de Tukey, tabela 2. 
Tabela 1: Teste de Tukey.para os grupos de tratamentos de médias dos países analisados; Brasil, China, Estados Unidos e Rússia.

\begin{tabular}{ccc} 
Grupos & Países & Médias (US\$/ton) \\
\hline $\mathrm{a}$ & Rússia & 1785 \\
$\mathrm{ab}$ & China & 1392 \\
$\mathrm{~b}$ & Estados Unidos & 1197 \\
$\mathrm{~b}$ & Brasil & 918,6 \\
\hline
\end{tabular}

Fonte: elaborado pelos autores.

Pelo teste de Tukey, tabela 2, pode-se verificar que os preços médios de frango são iguais nos tratamentos 2 e 3 , os quais representam os países China e Rússia, respectivamente, pois apresentaram mesma letra, "a". Por outro lado, os preços médios de frango são iguais nos tratamentos 1 e 4 , os quais representam os países Brasil e EUA, respectivamente, pois apresentaram a mesma letra, "b".

Como observado no item dois do trabalho, referente ao contexto mundial da produção, consumo, exportação e importação da carne de frango, a China e a Rússia são países essencialmente importadores, já o Brasil e os Estados Unidos são exportadores de carne de frango. Essa pode ser uma possível explicação para a semelhança entre os preços encontrados na pesquisa. A China importa cerca de $70 \%$ da soja disponível no mercado mundial, grande parte da oleaginosa é importada dos Estados Unidos, o mesmo ocorre com a Rússia, principal consumidora do frango oriundo dos Estados Unidos (COASUL, 2011).

Outras análises foram também ajustadas para os modelos de Regressão dos dados do Brasil, China, Rússia e EUA, através da função Stepwise do software R. Para isso, a variável resposta utilizada foi o Preço do Frango (P_Frango) e as variáveis independentes, o Preço do Milho (P_Milho) e o Preço da Soja (P_Soja).

No caso do Brasil, a variável Preço da Soja foi eliminada no processo de seleção das variáveis independentes, o que mostra que apenas o Preço do Milho contribui de forma significativa para explicar o Preço do Frango. Para o Brasil, o modelo ajustado foi o seguinte: $P \_F r a n g o=-6,204+7,335^{\star} P \_$Milho

$O R^{2}$ ajustado foi igual a 0,81 , além disso, o teste $F$, o qual testa o modelo de forma geral, foi significativo com $p$-valor $=0,0001$, mostrando que existe uma relação linear entre essas variáveis. Pode-se dizer ainda, que, para cada variação de US\$1/ ton no preço do milho, há uma variação de US $\$ 7,335$ /ton no preço do Frango.

Observando-se o trabalho de Miele (2002) percebe-se que o milho é utilizado em maior proporção do que a soja para a composição das rações dos frangos, em todas as fases de crescimento das aves. Além disso, embora o Brasil exporte milho e abasteça o mercado interno, não se destaca na produção do grão para estoque alimentar, figura quatro. Percebe-se, inclusive, um equilíbrio entre a produção e consumo do grão. 
Figura 04: Brasil - esquema de projeção de cenários da produção, consumo e exportação do milho - 2010 a 2021 pelo MAPA.

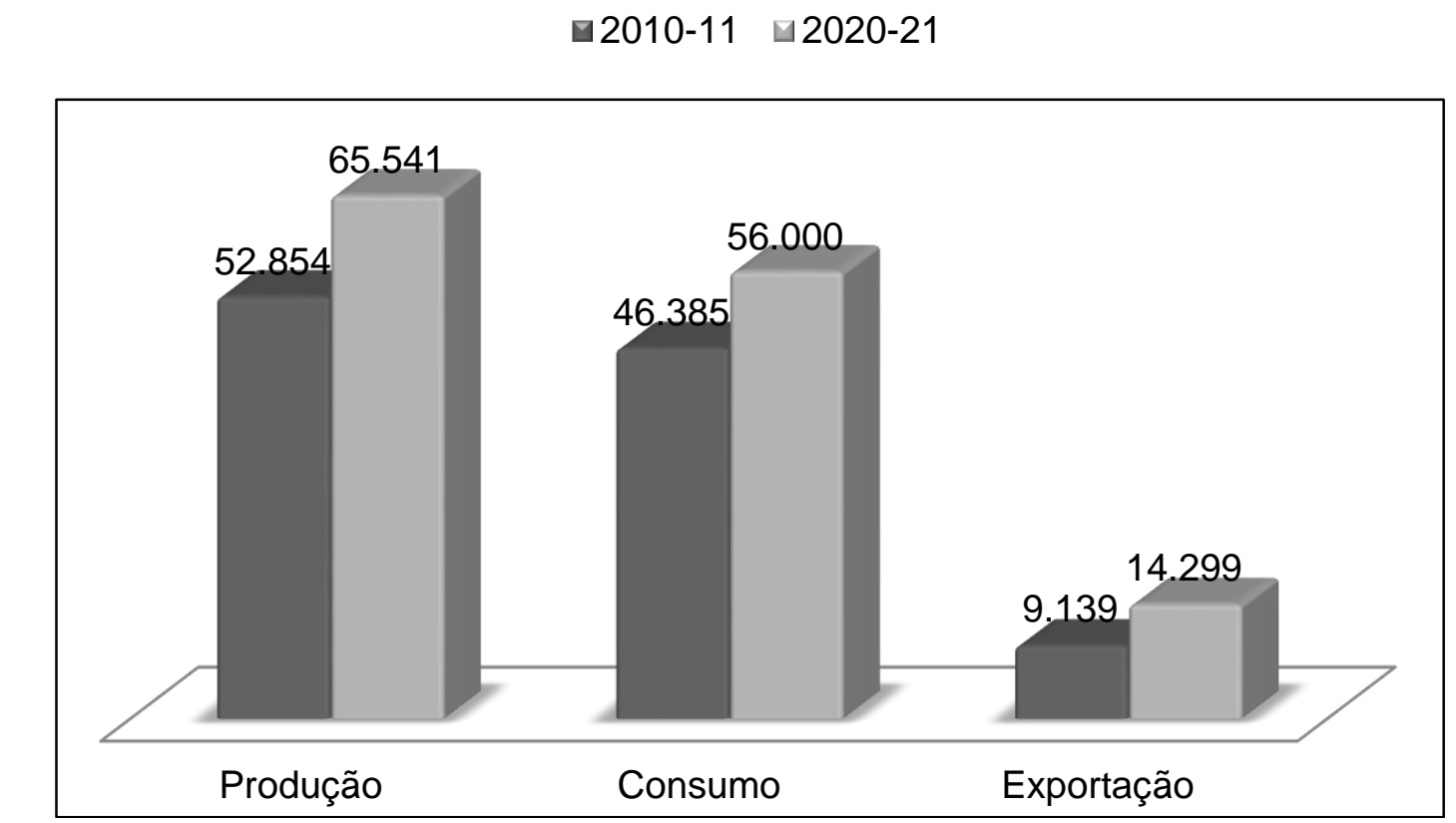

Fonte: MAPA - Assessoria de Gestão Estratégica (2011).

Para a China, a variável que contribui de forma significativa para explicar o preço do frango foi o preço da soja; a variável preço do milho foi eliminada no processo de seleção de variáveis. Para a China, o modelo ajustado foi: $P \_F r a n g o$ $=-444,011+4,521^{*} P \_$Soja

O teste $F$ para o modelo foi significativo, com $R^{2}$ ajustado igual a 0,92. Segundo o modelo, uma variação de US\$ 1 /ton no preço da soja implica em uma variação de US\$ 4,251 /ton no preço do frango. Novamente repete-se a explicação das importações para o modelo ajustado para a China, o fator soja foi o mais relevante para o preço do frango, provavelmente em virtude da importação do grão pelo país. Resultado similar ocorreu no caso da Rússia, em que a variável preço da soja contribui de forma significativa para explicar o preço do frango, enquanto a variável preço do milho foi eliminada no processo de seleção de variáveis. $O$ modelo ajustado se mostrou significativo pelo teste $F$, com $R^{2}$ ajustado igual a 0,89 .

Sua descrição segue a seguir: $P \_$Frango $=845,839+4,034^{*} P \_$Soja. Ainda pode-se dizer que, para cada variação de US\$1/ton no preço da soja, tem-se uma variação de US $\$ 4,034$ /ton no preço do frango.

Para concluir as avaliações sobre as relações entre o preço do frango e os preços da soja e do milho, nos países pesquisados, foi realizada uma análise desses preços para os dados dos EUA. Porém, com o teste de correlação de Pearson, o qual testa a existência ou não de correlação significativa entre duas variáveis observou-se que os testes foram não significativos ao nível de $5 \%$ de probabilidade, ou seja, as correlações entre o preço do frango versus o preço da soja e preço do frango versus o preço do milho não são significativas, então se optou por não realizar a análise de regressão, pois isso indica que as variáveis independentes não contribuem de forma significativa para explicar a variável resposta preço do frango. A correlação existe, é positiva, ou seja, o aumento no 
preço do milho e da soja implicam no aumento do preço do frango, mas isso não ocorre de forma significativa, considerando um nível de 5\%. Então, nos Estados Unidos, o preço da soja e do milho contribuem para o preço do frango, mas não de forma significativa, no período de 2000 a 2009.

\section{CONSIDERAÇÕES FINAIS}

O artigo teve como principal objetivo apresentar o panorama estatístico de elementos que contribuem na formação global dos preços, além do contexto mundial da produção, consumo, exportação e importação da carne de frango.

Em virtude das análises demonstrarem que os grãos são importantes para o preço final da carne de frango, verificou-se que o milho e a soja são componentes das rações animais influenciando significativamente o preço final da carne de frango no Brasil, China e Rússia.

Este estudo demonstrou como o milho teve um caráter importante no balanço do preço final da carne de frango brasileira, em contrapartida a soja mostrou-se mais relevante para o preço final da carne de frango da China e da Rússia. Já, os Estados Unidos, tiveram correlação positiva entre as variáveis; preço do milho, da soja e do frango, mas não foram significativas ao nível de $5 \%$, no período de 2000 a 2009.

Assim, finalmente pode-se concluir que através da pesquisa para conhecer elementos que influenciam na incerteza dos preços da carne de frango também foi possível compreender que os ambientes de negociação global são complexos. Por esse motivo a decisão de concentrar-se em poucas variáveis foi de fundamental importância para a composição da análise de regressão múltipla. As análises com a adição de muitas variáveis podem correr o risco da ocorrência de multicolinearidade.

\section{REFERÊNCIAS BIBLIOGRÁFICAS}

ABIMAQ. Associação Brasileira da Indústria de Máquinas e Equipamentos. Definição de Antidumping. Ano 2014. Disponível em: http://www.abimaq.org.br/site.aspx/Antidumping

BALTZER, K.; HANSEN, H.; LIND, M. A note on the causes and consequences of the rapidly increasing international food prices. Institute of Food and Resources Economics. Copenhagen, Ano 2008, pag. 1. Disponível em:

http://www.researchgate.net/publication/237321727_A_note_on_the_causes_a nd_consequences_of_the_rapidly_increasing_international_food_prices/links $/ 0$ deec52ce717be31c1000000

COOPERATIVA AGROPECUÁRIA SUDOESTE LTDA. (COASUL). Rússia e China seguem com participação menor nas exportações de frango dos EUA. Avicultura, notícias, 2011. Disponível em: http://www.coasul.com.br/russiae-china-seguem-com-participacao-menor-nas-exportacoes-de-frango-dos-eua/. 
DUNCAN, R. B. Characteristics of organizational environments and perceived environmental uncertainty. Administrative Science Quarterly, Ano 1972, Nro. 17, Vol. 13 pag. 313.

EMPRESA BRASILEIRA DE PESQUISA AGROPECUÁRIA/CENTRAL DE INTELIGÊNCIA DE AVES E SUÍNOS (EMBRAPA/CIAS)/Food and Agriculture Organization of United Nations (FAO). Mapa da distribuição do efetivo de frangos (em cabeças) no ano de 2010. Disponível em: http://www.cnpsa.embrapa.br/cias/.

FOOD AND AGRICULTURE ORGANIZATION OF UNITED NATIONS. (FAO) World Livestock 2011 - Livestock in food security. Rome, FAO, 2011. Disponível em: https://www.fao.org.br/. FOOD AND AGRICULTURE

ORGANIZATION OF UNITED NATIONS (FAO). Food Outlook 2011. Disponível em: https://www.fao.org.br/.

FOOD AND AGRICULTURE ORGANIZATION OF UNITED NATIONS (FAO) Statistical Database. (FAOSTAT), 2012. Disponível em: https://www.faostat.org.br/.

HAIR, Jr.et al. Análise Multivariada de Dados. Porto Alegre: Bookmann, 2005, $593 \mathrm{p}$.

INTERNATIONAL MONETARY FUND (FMI). World economic outlook: a survey by the staff of the International Monetary Fund, Washington, DC: International Monetary Fund, 2011. Disponível em: http://www.imf.org/external/pubs/ft/weo/2012/02/pdf/text.pdf

JOHNSON, R. A.; WICHERN, D. W. Applied multivariate statistical analysis. 5th ed. Upper Saddle River, New Jersey: Prentice-Hall, 2002, 767 p.

JUSOH, R. (2010). The influence of perceived environmental uncertainty, firm size, and strategy on multiple performance measures usage. African Journal of Business Management, Ano 2010, Nro.10, Vol. 4, p. 1972-1984. Disponível em://www.academicjournals.org/ajbm.

LYRA, G. B.; ODA-SOUZA, M.; VIOLA, D. N. Modelos lineares aplicados à estimativa da concentração do material particulado (PM10) na cidade do Rio de Janeiro, RJ. Rev. bras. meteorol., Ano 2011, Nro.3, vol.26, p. 392.

MINISTÉRIO DA AGRICULTURA PECUÁRIA E ABASTECIMENTO (MAPA). Brasil: projeções do agronegócio 2010/2011 a 2020/2021. Brasília: Ministério da Agricultura Pecuária e Abastecimento - Assessoria de Gestão Estratégica. Disponível em http://www.agricultura.goVol.br/arq_editor/file/Ministerio/gestao/projecao/Projec oes\%20do\%20Agronegocio\%20Brasil\%202011-20012\%20a\%2020212022\%282\%29.pdf.

MIELE, M. et al. Coeficientes técnicos para o cálculo do custo de produção de frango de corte. Comunicado Técnico 483, EMBRAPA, Santa Catarina, Dezembro, 2010, ISSN 0100-8862.

MIELE, M. ; GIROTTO, A. F. Análise da situação atual e perspectivas da avicultura de corte. Ave World, Paulínia, Ano 2005, v. 14, p. 16. 
MILLIKEN, F. J. Three types of Perceived Uncertainty about the Environment: State, Effect, and Response Uncertainty. Academy of Management Review, Ano 1987 Nro. 1, Vol. 12, p.133-143.

MONTGOMERY, D. C.; PECK, E. A.; VINING, G. G. Introduction to linear regression analysis. 4. ed. New York: John Wiley \& Sons, 612p, 2006.

MORETTIN, P. A.; TOLOI, C. Análise de Séries Temporais. São Paulo: Blucher, 2006, $538 \mathrm{p}$.

NUNES, F. Mesmo com a crise momentânea, frango tem futuro promissor. Site Avicultura Industrial. Brasil, Seção Economia, Eventos e Cursos, 2012. Disponível em: http://www.aviculturaindustrial.com.br/noticia/mesmo-com-acrise-momentanea-frango-tem-futuro-promissor/20120913091838_T_873.

ORGANISATION FOR ECONOMIC CO-OPERATION AND DEVELOPMENT (OECD)/FOOD AND AGRICULTURE ORGANIZATION OF THE UNITED NATIONS (FAO) (OECD/FAO) Agricultural Outlook, 2012. Disponível em: http://www.oecd-ilibrary.org/agriculture-and-food/oecd-fao-agricultural-outlook2012_agr_outlook-2012-en

O'NEILL, J. Building Better Global Economic BRICs. Global Economics, No.66, London, Goldman Sachs Economic Research Group, 16 p., 2001. Disponível em: http://www.goldmansachs.com/our-thinking/archive/archive-pdfs/build-betterbrics.pdf

$R$ DEVELOPMENT CORE TEAM $R$. A language and environment for statistical computing. R Foundation for Statistical Computing, Vienna, Austria, 2011. ISBN 3-900051-07-0. Disponível em: http://www.R-project.org/.

RODRIGUÉZ, H. A. R.. Strategic Change for Turbulent Environments (In Spanish). Revista de la Facultad de Ciencias Económicas de la Universidad Militar Nueva Granada, Vol. 18, No. 1, 2010. Disponível em: http://ssrn.com/abstract=1671707

UNITED STATES DEPARTMENT OF AGRICULTURE (USDA)/EMPRESA BRASILEIRA DE PESQUISA AGROPECUÁRIA/CENTRAL DE INTELIGÊNCIA DE AVES E SUÍNOS (EMBRAPA/CIAS), 2012. "Consumo mundial de carne de frango", nos anos 2010 e 2012. - Disponível em: http://www.cnpsa.embrapa.br/cias/.

UNITED STATES DEPARTMENT OF AGRICULTURE (USDA). Empresa Brasileira de Pesquisa Agropecuária/Central de Inteligência de Aves e Suínos (EMBRAPA/CIAS), 2012.- "Distribuição do efetivo de frangos (em cabeças) no ano de 2010, no Brasil." Disponível em: http://www.cnpsa.embrapa.br/cias/.

UNITED STATES DEPARTMENT OF AGRICULTURE (USDA)/EMPRESA BRASILEIRA DE PESQUISA AGROPECUÁRIA/CENTRAL DE INTELIGÊNCIA DE AVES E SUÍNOS (EMBRAPA/CIAS), 2012 - “Importações mundiais de carne de frango." Disponível em: http://www.cnpsa.embrapa.br/cias/.

UNITED STATES DEPARTMENT OF AGRICULTURE (USDA). EMPRESA BRASILEIRA DE PESQUISA AGROPECUÁRIA/CENTRAL DE INTELIGÊNCIA DE AVES E SUÍNOS (EMBRAPA/CIAS), 2012 - "Produção mundial da carne de frango em 2012". Disponível em: http://www.cnpsa.embrapa.br/cias/. 
UNITED STATES DEPARTMENT OF AGRICULTURE (USDA) (2012). EMPRESA BRASILEIRA DE PESQUISA AGROPECUÁRIA/CENTRAL DE INTELIGÉNCIA DE AVES E SUÍNOS (EMBRAPA/CIAS), 2012. - "Total de exportações dos principais países exportadores de carne de frango." Disponível em: http://www.cnpsa.embrapa.br/cias/. 